\title{
50 \\ The Economic Value of Flexibility when there is Disagreement
}

\author{
Arnoud W.A. Boot ${ }^{1}$ \\ Anjan V. Thakor ${ }^{2}$
}

1 Faculty of Economics and Econometrics, University of Amsterdam, and Tinbergen Institute,

2 University of Michigan Business School. 
Tinbergen Institute

The Tinbergen Institute is the institute for economic research of the Erasmus Universiteit Rotterdam, Universiteit van Amsterdam and

Vrije Universiteit Amsterdam.

Tinbergen I nstitute Amsterdam

Keizersgracht 482

1017 EG Amsterdam

The Netherlands

Tel.: +31.(0)20.5513500

Fax: $\quad+31 .(0) 20.5513555$

Tinbergen Institute Rotterdam

Burg. Oudlaan 50

3062 PA Rotterdam

The Netherlands

Tel.: $\quad+31 .(0) 10.4088900$

Fax: $\quad+31 .(0) 10.4089031$

Most TI discussion papers can be downloaded at

http://www.tinbergen.nl 
First Draft, June 2002

This Draft, November 2002

\section{THE ECONOMIC VALUE OF FLEXIBILITY WHEN THERE IS DISAGREEMENT}

by

Arnoud W.A. Boot* and Anjan V. Thakor**

* University of Amsterdam

** University of Michigan Business School

Acknowledgments: We thank Christa Bouwman, Josh Coval, Amrita Nain, Radhakrishnan Gopalan, Raghu Rajan, Andrei Shleifer, and participants at the 2002 Colorado Summer Finance Conference for helpful suggestions on an earlier version of the paper. 


\title{
THE ECONOMIC VALUE OF FLEXIBILITY WHEN THERE IS DISAGREEMENT
}

\begin{abstract}
We develop an economic theory of "flexibility", which we interpret as the discretion or ability to make a decision that others disagree with. We show that flexibility is essentially an option for the decisionmaker, and can be valued as such. The value of the flexibility option is decreasing in the extent to which the decisionmaker's future decision-relevant opinion is correlated with the opinions of others who may be able to impede the decision.

We argue that flexibility drives economic decisions in a significant way. The applications we consider are: the entrepreneur's choice of flexibility in the initial mix of financing raised, the use of flexibility to understand differences in security design and the firm's security-issuance decision, the impact of flexibility on the use of collateral in lending, the role of flexibility in capital budgeting decisions, the effect of flexibility considerations in the design of contracts in a principal-agent setting, the interpretation of "power" and conformity in organizations in the context of flexibility, and the choice between private an public ownership in the context of flexibility.
\end{abstract}




\section{THE ECONOMIC VALUE OF FLEXIBILITY WHEN THERE IS DISAGREEMENT}

"There is only one success - to be able to spend your life in your own way"

Christopher Morley

\section{INTRODUCTION}

Casual observation tells us that people value flexibility. Managers sometimes refer to it as "elbow room", the ability to alter operating decisions and change strategic direction when circumstances change. Microsoft, which currently has $\$ 40$ billion in cash and no long-term debt, argues that this is necessary to give senior management the flexibility to take advantage of future opportunities that may arise. Tesco, the successful retailer, reports that the strong cash flow from its UK operations gave it "the financial strength to move quickly and grasp opportunities where they become available" ${ }^{\prime \prime}$ Banks routinely build up capital levels well in excess of regulatory capital requirements. For example, since 1995, essentially none of the 100 largest U.S. banking firms have been constrained by regulatory capital standards (see Flannery and Rangan (2002)). Within organizations, more senior executives are given greater discretion over decisions, which means they have more flexibility to do what they want, relative to those at lower levels. This is sometimes referred to as "real authority" (e.g. Aghion and Tirole (1997)).

But what exactly is "flexibility"? We do not have an economic theory of flexibility to inform us. One of our objectives is to provide such a theory. The theory pivots on the intuition that flexibility is the ability to make the decision one thinks is best when others disagree. This is not a question of who is right and who is wrong. It is a question of divergent beliefs about the optimal course of action, with insufficient time or objective data for beliefs to converge. It is a

\footnotetext{
${ }^{1}$ See Child (2002). Tadelis (2002) uses flexibility in a very different sense from ours by focusing on the ability to make ex post changes with incomplete contracting in the context of the make-or-buy decision.
} 
matter of intuition. The decisionmaker may be convinced that a particular action is optimal, and yet other reasonable people may feel equally strongly that it is not. The ability to take the desired action in the face of such disagreement is what flexibility is all about. ${ }^{2}$

We find that flexibility is isomorphic to an option. The option is worthless to the decisionmaker when others agree with the decisionmaker; it is "in the money" precisely when there is disagreement. That is, the value of the flexibility option to the decisionmaker stems from the ability to do what the decisionmaker thinks is right even when others think it is wrong; this value is increasing in the likelihood that others will disagree with the decisionmaker.

One could argue that people value flexibility for its own sake. That is, they derive positive utility from getting their way when others disagree with them because it signifies a form of power. While we interpret flexibility as organizational power in one of our applications, we show that it is not necessary to attach an exogenous utility benefit to flexibility for it to be valued by the decisionmakers.

It is important to recognize that flexibility has nothing to do with asymmetric information (Akerlof (1970)) problems per se. The decisionmaker desires flexibility not because he has better information than those who delegate decisions to him. Rather, the decisionmaker recognizes the possibility of future disagreement even when all concerned are conditioning their opinions on the same incremental information set. Thus, an essential ingredient of our theory is the possibility that the same piece of information may be processed very differently by different people. A variety of factors, that we discuss in the next section, may account for this.

Flexibility also differs from agency problems, which are created by a divergence of

\footnotetext{
${ }^{2}$ An illustration of how perceived disagreement leads decisionmakers to contemplate ways to acquire the flexibility to overcome such disagreement is provided in the following quotation attributed to Jack Welch, former CEO of General Electric,

"It's best to present big ideas without time frames or rigidly defined goals, because there is resistance to every idea that's different from the current norm. If you allow the naysayers to measure and quantify your idea, they can come back and blow it away before it has a chance to work.... The leader's unending responsibility must be to remove every detour, every barrier to ensure that the vision is first clear and then real". See Lowe (1998).
} 
interests between the agent and the principal (e.g. Holmstrom (1979)). In our analysis, we explicitly assume that both the decisionmaker and those delegating to him are maximizing the same terminal payoff. That is, their interests are perfectly aligned. But their beliefs are not.

Having said this, we do believe that interesting insights may emerge from juxtaposing flexibility with problems of asymmetric information and agency. We do this in some of our applications.

A stream of literature somewhat related to our concept of flexibility is the debate about rules versus discretion (see Modigliani (1964), Kydland and Prescott (1977), Goldfeld (1982), Barro (1986)). The desirability of rules over discretion has been discussed largely in the context of macroeconomic policy. In this literature, a discretionary policy seeks to select the best decision, given the information available at the time. Rules, by contrast, are seen as a form of commitment to a binding contract that prespecifies the actions that someone will take, possibly contingent on some publicly-observable exogenous variables. Thus, discretion is a special case of a rule or contract in which none of today's provisions restrict a person's future actions.

The standard argument in favor of discretion is that it may be difficult to anticipate all possible state contingencies in advance and hence a rigid rule may preclude taking advantage of information that arrives unexpectedly after the rule was formulated. The argument in favor of rules is that they represent precommitments to avoid problems caused by the dynamic inconsistency of optimal plans.

The view of discretion in this literature is very different from our notion of flexibility. In particular, in the rules-versus-discretion literature, discretion is seen as an optimal control problem where, at each point in time, the decision selected is best, given the current state and given that decisions will be optimally selected in the future. While discretion in this literature means flexibility for the decisionmaker to do what is best given the information available, it is 
not the disagreement-based flexibility that we study. We view discretion as the option or ability to take the desired action in the face of disagreement. ${ }^{3}$

We show in our analysis that flexibility is valuable to the decisionmaker, and our premise is that flexibility considerations affect the vast majority of decisions. The more uncertain the decisionmaker is about the future value of a decision-germane payoff and the higher the probability of disagreement, the more flexibility is valued. Thus, the potential applications of flexibility are far too numerous for us to exhaustively discuss in this paper. However, we examine a few applications to illustrate how we can use flexibility to gain insights into various economic phenomena.

The first application is the entrepreneur's choice of initial financing. We show that flexibility in this context concerns the entrepreneur's ability to make decisions that financiers may object to. Flexibility is an ex ante choice variable for the entrepreneur. The tradeoff the entrepreneur faces in making this choice is as follows. On the one hand, greater flexibility benefits the entrepreneur because it increases the value of the flexibility option to him. On the other hand, greater flexibility leads to a higher cost of capital raised from financiers.

A related application is the role of flexibility in the context of the design and issuance of financial securities. We argue that equity provides the firm's manager greater flexibility than debt, but carries a higher cost of capital. Thus, which security the manager decides to issue will be dictated by the value of the flexibility option to the manager at that point in time.

Our third application is secured lending. We argue that the potential loss of flexibility associated with pledging an asset as collateral may explain why unsecured loans are observed despite the obvious benefit of a lower borrowing cost with a secured loan.

\footnotetext{
${ }^{3}$ A somewhat related notion of flexibility is used in Aghion, Alesina and Trebbi (2002) who examine the problem of how much "unchecked power" society should delegate to its leaders, i.e., the socially optimal degree of checks and balances. The tradeoff in that paper is that the more power the leader is given, the less easily he can be blocked by legislators, but the higher is the probability that a "bad" leader will cause some to suffer losses from expropriation.
} 
We then apply the notion of flexibility to capital budgeting. Most organizations have well-specified rules for allocating capital to projects, such as explicit approval "toll gates" at various stages of the project, and requirements related to forecasts of net present value (NPV) and internal rates of return (IRR). The question we address is: how much discretion should be given to the decisionmaker to invest in a project that does not satisfy the explicit criteria specified for project approval? In other words, to what extent should the decisionmaker's intuition be allowed to supplant "fact-based" decisionmaking? The more the decisionmaker is allowed to rely on his intuition, the more flexibility he has. We show that this decision about the design of capital budgeting depends on the "nature" of the project being analyzed.

Our fifth application is the principal-agent problem. The existing literature has focused on determining the optimal contract, which is a payoff-sharing rule that achieves the optimal balance between risk sharing among the principal and the agent and incenting the agent to take an action the principal desires (see Prendergast (1999) for a review). The flexibility perspective reveals that there is another potentially important dimension to contract design, namely the degree of flexibility the principal gives to the agent. Since flexibility affects both the risk sharing and the effort-incentive aspects of the contract, it must be simultaneously determined ex ante along with the payoff-sharing rule. We discuss the factors that affect the principal's choice of how much flexibility to give to the agent.

Our next application is "power" or "real authority" in organizations. We argue that one interpretation of power is to have greater flexibility to make decisions that one thinks are right even when these decisions conflict with organizational rules or the views of others. We present a framework in which employees who are higher up in the organizational hierarchy are given greater flexibility. In this sense, our analysis can be viewed as endogenizing the private benefit of control, with the important distinction that control is not valued because it privately benefits 
the decisionmaker, but because of the flexibility it offers in maximizing firm value.

In our penultimate application, we explain how flexibility can be used to understand why people conform excessively in organizations, i.e., why we have so many yes-men.

Finally, we discuss how flexibility considerations may affect a firm's choice between private and public ownership. We argue that a firm with a sufficiently low stock price may prefer private ownership over public ownership.

The rest of the paper is organized as follows. Section II is devoted to a discussion of the literature on disagreement. In Section III, we develop the framework to assess the economic value of flexibility. Section IV discusses the financial applications of flexibility: the entrepreneur's choice of flexibility, the role of flexibility in security design and issuance, and the role of flexibility in capital budgeting. Section V takes up the other applications: the impact of flexibility on contract design in a principal-agent setting, using flexibility to understand "power" in organizational hierarchies, applying flexibility to understand organizational conformity, and understanding the choice between private and public ownership based on flexibility. Section VI concludes. All proofs are in the Appendix.

\section{WHY PEOPLE DISAGREE}

The starting point of our analysis is that two agents looking at the same information may disagree on the optimal course of action implied by that information. In this section, we briefly review the literature that has provided insights into why people disagree.

There are at least five distinct literatures that are relevant: the failure of beliefsconvergence via rational learning, strategic disagreement in a game-theoretic setting, disparate interpretations of the same information, psychological reasons for disagreement, and bounded rationality. The first literature deals with disagreement arising from a lack of convergence of beliefs, the overall message being that rational learning does not necessarily lead to agreement. 
This literature begins with Aumann's (1976) definition of common knowledge and his proof that two "like-minded" individuals cannot "agree to disagree" if they start with a common prior belief, update their beliefs on the basis of private information and arrive at posteriors that are common knowledge; their posterior beliefs must coincide (see Bonanno and Nehring's (1997) survey). Since then, disagreement has been rationalized primarily by relaxing Aumann's assumptions. For example, Allen and Gale (1999) and Morris (1995) rely on non-uniform prior beliefs, while Hirshleifer, Lim and Teoh (2002) assume that different agents may have different levels of "attentiveness" and information-processing capabilities.

A more fundamental challenge to the Aumann thesis that rational learning must lead to agreement was provided by Miller and Sanchirico (1997). They posed the following question. Suppose we randomly draw two agents from a population and ask them to observe an unfolding, infinite sequence of zero and ones. If each agent starts with a prior belief about the true sequence and updates this belief based on the revelation of successive observations, what is the chance that the two agents will eventually agree on the probability that the next draw is a one? Their surprising answer is that this probability is zero. More formally, they show that under a fairly general definition of what it means to draw priors randomly, the probability of the two priors (weakly) merging is zero. ${ }^{4}$

The second literature views disagreement as a strategic outcome in a game-theoretic setting. Crawford (1982) develops a theory of disagreement in bargaining that is based on

\footnotetext{
${ }^{4}$ They point out that the foundations of the "rational learning" literature go back to the Blackwell and Dubins (1962) theorem that if $\mathrm{Q}$ and $\mathrm{P}$ are measures on an infinite product space and $\mathrm{Q}$ is absolutely continuous with respect to $\mathrm{P}$, then Q and P will almost surely "merge" in the sense that the "distance" between these revised probabilities, conditional on the full continuation of the sequence, will limit to zero as the sequence unfolds. Kalai and Lehrer (1993) rely on this result to claim that rational learning leads to Nash equilibrium. In a subsequent paper, Kalai and Lehrer (1994) introduce "weak merging", which is convergence of conditional probabilities based on only the next period's draw as opposed to the infinite future. What Miller and Sanchirico (1997) show is that the assumptions that lead to the convergence result in the rational-learning literature are perverse in the sense that assuming absolute continuity is the same as assuming merging, so that the inevitability of agreement with rational learning is more an assumption than a result; obtaining agreement as a consequence of Baysian updating requires "extra rational" restrictions on human behavior.
} 
Schelling's view of the bargaining process as a struggle between bargainers to commit themselves to favorable bargaining positions. He shows that even though a bargaining impasse is inefficient and avoidable, it can still arise as a consequence of rational behavior when successful commitment is uncertain and irreversible. That is, disagreement need not be attributable solely to divergent beliefs. Evidence about disagreements in labor-management negotiations provided by Farber and Bazerman (1989) lends credence to the view that disagreement may be caused by factors other than differences in beliefs, including the kind of strategic factors identified by Crawford (1982).

The third literature that has dealt with disagreement is that on trading in financial markets. Kandel and Pearson (1995) develop a model of trade around public announcements of information in which agents interpret the same public information differently. They show that the model produces predictions that are consistent with the empirical evidence they provide on the relationship between the volume of trade and stock returns around public announcements. Bamber, Barron and Stober (1997) also investigate the relationship between trading volume and earnings announcements and find that trading volume arises because of investor disagreement. Interestingly, they identify three distinct aspects of disagreement and find that each plays a role in explaining trading volume around earnings announcements. The three aspects are: dispersion in prior beliefs (cross-sectional variation in expectations before the earnings announcement), divergence in beliefs (change in the dispersion of beliefs), and beliefs jumbling (investors' beliefs change positions relative to each other). These papers illustrate the rich variety of ways in which disagreement can arise.

The fourth literature is psychology, where both the circumstances in which people tend to disagree and the underlying root causes of disagreement have been studied. As for circumstances, disagreement in joint decisionmaking may occur due to strategic polarization, as 
shown in a game-theoretic setting by Kalai and Kalai (2001). Another situation in which disagreement is likely is when expressed opinions are difficult to invalidate ex post on the basis of facts or the opinions of others (Alicke and Doherty (1992)).

At least four root causes of disagreement have been analyzed in psychology. The first is a "propensity for uniqueness" in decisionmakers. That is, decisionmakers have a strong tendency to consider problems as unique and ignore historical statistics in evaluating current plans (Kahneman and Lovallo (1993)). A second reason is the tendency of people to ignore information that contradicted earlier beliefs. Studies of the decisionmaking process that contributed to the escalation of the Viet Nam war have shown that leaders paid more attention to information that was more compatible with their earlier decisions (White (1971)). These two reasons may explain why the beliefs of different agents don't converge as predicted by Aumann (1976) and why disagreement may persist. A third reason is that agents rely heavily on their "intuition" and they disagree because each has a different intuition about the appropriate solution to a problem ${ }^{5}$. This is very much the way we model disagreement in this paper. The fourth root cause of disagreement is identified by Stumpf and Dunbar (1991) who focus on differences in personality types to understand disagreement. In their behavioral simulation of decisionmaking involving 407 participants, they found that individuals with different personality-type preferences (i.e., sensing-thinking, intuition-thinking, sensing-feeling, and intuition-feeling) take patterns of actions that differ based on specific biases. That is, disagreement is driven by differences in cognitive biases, such as selective perception, overconfidence, social desirability, reasoning-by-analogy, or even ideology (as in Mullainathan and Shleifer (2002)). This may be one way to interpret the evidence provided by Fuchs, Krueger and Poterba (1997). They report

\footnotetext{
${ }^{5}$ Clarke and Mackaness (2001) show that there are three important aspects of intuition as a way in which individuals "cut through" a decision situation to arrive at an "unexplained" relationship between information inputs and cognition. First, they appear to trade off depth of information for breadth. Second, they use personal experience and surrogate indicators to rationalize their decisions. Finally, they use different underlying (intuition-related) decision processes that represent the basis for disagreement.
} 
the results of surveys of specialists in labor economics and public economics at 40 leading research universities in the U.S. The authors found considerable disagreement among economists about policy proposals. Economists' positions on policy appear to be more closely related to their personal values than to their estimates of relevant economic parameters or to their political party identification.

Finally, the fifth literature in which disagreement has been studied is that on bounded rationality. Kurz (1994a) studies "rational belief equilibria" in which agents are rational but select diverse forecast functions; each forecast function is rational in the sense that it is based on a theory that cannot be rejected by the data. An application of the rational-beliefs paradigm to security design appears in Garmaise (2001) who studies the security-design problem of a cashconstrained firm facing investors with diverse beliefs. Investors' beliefs vary and yet are rational in the sense of Kurz (1994b). The paper shows that with many investors, optimal securities under rational beliefs maximize investor differences of opinion.

To summarize, the notion that people disagree is not new, and various perspectives have emerged on why they disagree. For our purposes, the precise cause of disagreement is not important. What matters is that there is scope for disagreement among individuals even when they are faced with the same incremental information, and this is recognized a priori by both the decisionmaker and others.

\section{AN ECONOMIC MODEL OF FLEXIBILITY}

In this section we present a general model of flexibility, and define, what we call, the flexibility option.

\subsection{The Players and Their Preferences}

There are two key players in the model: the decisionmaker and those who delegate the decision to the decisionmaker. We will refer to the decisionmaker as the "insider" and those 
who delegate the decision as "outsiders." We do not explicitly model why delegation occurs, although the reasons for delegation are quite transparent in the applications we discuss. "Flexibility" will refer to the ability of the insider to act independently of the views of the outsiders. Everybody is risk neutral; this assumption is innocuous and serves merely to simplify the analysis.

\subsection{Model Description}

The key assumptions in this general model are that the insiders and outsiders may disagree, and that outsiders may veto the planned course of action of the insider. The "flexibility option" is the value that the insider is willing to pay to reverse or prevent a veto by outsiders. We call this an option because flexibility here pertains only to the situation in which the insider wishes to undertake an investment that outsiders do not. The asymmetry that creates the option is that if the insider thinks the investment is a bad idea, it will never be pursued, regardless of what outsiders think, and if the insider and outsiders both agree it is a good idea, the insider will make the investment. That is, flexibility is the option the insider has to disregard the opinion of outsiders. We model this as follows. At $t=0$, a potential decision is anticipated at $t=1$. This can be a course of action, say an investment. At $\mathrm{t}=1$, the insider observes a signal $\mathrm{x}$ about the terminal payoff from the investment and has to decide on the investment opportunity. The insider wants to undertake the investment if $x \geq S$, where $S$ is a particular threshold. We could interpret $\mathrm{S}$ as the investment, where $\mathrm{x}-\mathrm{S}$ is the NPV of the investment. In an options context, $\mathrm{S}$ is the strike price of the option. The terminal payoff on the investment is observed at $t=2$.

Outsiders have their own independent assessment, $y$. If $y \geq S$, they consider the investment worthwhile. If $y<S$, they seek to veto the investment. The signals $x$ and $y$ are possibly correlated, with a joint probability density function $\mathrm{q}(\mathrm{x}, \mathrm{y})$. However, both the insider and outsiders base their decisions solely on their own signals. They do not use each other's 
signal to update their own priors. That is, $\mathrm{x}$ and $\mathrm{y}$ are their respective assessments of the project, and the difference between $\mathrm{x}$ and $\mathrm{y}$ measures the extent of disagreement between the insider and outsiders at $\mathrm{t}=1$. Both insiders and outsiders seek to maximize the expected payoff at $\mathrm{t}=2$.

It is useful at this stage to pause and interpret the signals $\mathrm{x}$ and $\mathrm{y}$. One way to think about $\mathrm{x}$ and $\mathrm{y}$ is that they are simply differing opinions about the future realization of a state variable, as in say, Allen and Gale (1999). More specifically, we view x as representing the insider's intuition about the value of the investment opportunity (e.g. Clark and Mackaness (2001)). It is a belief, and not something the insider can communicate to outsiders on the basis of facts or documents or research findings. One could use a similar interpretation about y. We could allow the insider to observe $\mathrm{y}$ and outsiders to observe $\mathrm{x}$, and yet neither party is willing to update or change their beliefs based on their observations of the other party's signal. This may be viewed as a sort of "self-righteousness", but it describes a situation in which two people interact and each has a different intuition about what will happen in the future, with neither party able to change the other's mind based on the facts. ${ }^{6}$ An example would be the ubiquitous situation of two people placing opposite bets on a particular outcome, like a football game. Hence, we are explicitly precluding situations of asymmetric information in which one party knows more than the other, both parties recognize the informationally-advantaged party, and the less-informed party immediately updates his information set if he has access to the information possessed by the better-informed party.

The potential disagreement is anticipated at $t=0$. The key question now is what value the insider attaches at $t=0$ to being able to make the decision he wants over the objection of outsiders. This is what we call flexibility. With flexibility, the insider can execute his own strategy even if there is disagreement between him and the outsiders. In specific situations,

\footnotetext{
${ }^{6}$ This will be particularly true if some of the information that is exchanged is "soft" or subjective.
} 
flexibility can be guaranteed by choosing a particular policy at $t=0$; e.g. excess liquidity in order to maintain financial flexibility for future investment opportunities. Here in the general model, we introduce the notion of a "flexibility option", which is the value to the insider of avoiding a potential veto by outsiders. Given below is the sequence of events in the model.

\section{Figure 1: Sequence of events}

time

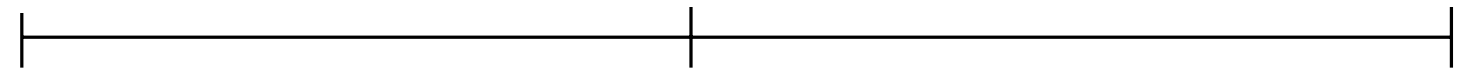

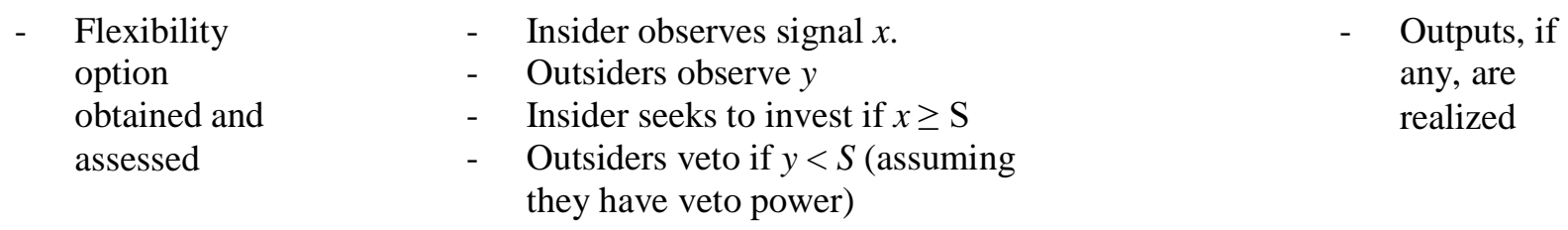

\subsection{Analysis}

We proceed as follows. With a zero discount rate between $t=0$ and $t=1$, the total expected net present value of the investment opportunity without an outsider veto as assessed by the insider is

$$
E(V)=\int_{s}^{\infty}[x-S] g(x) d x
$$

where $g(x)=\int_{-\infty}^{+\infty} q(x, y) d y$

and $\mathrm{q}(\mathrm{x}, \mathrm{y})$ is the joint density function of $\mathrm{x}$ and $\mathrm{y}$, with cumulative distribution function $\mathrm{Q}(\bullet, \bullet)$.

Similar to $g(x)$, the marginal density of $y$, is $h(y)=\int_{-\infty}^{\infty} q(x, y) d x$.

The value $\mathrm{E}(\mathrm{V})$ can be decomposed as follows (we let the inner integral be over $\mathrm{x}$ and the outer integral over y), 


$$
\begin{aligned}
& E(V)=\int_{s}^{\infty} \int_{s}^{\infty}[x-S] q(x, y) d x d y+\int_{-\infty}^{s} \int_{s}^{\infty}[x-S] q(x, y) d x d y \\
& \equiv A+F
\end{aligned}
$$

represents the value of the investment opportunity when there is agreement, and the expression $\mathrm{F}$ is the flexibility option, i.e.

$$
F \equiv \int_{-\infty}^{s} \int_{s}^{\infty}[x-S] q(x, y) d x d y
$$

which has value when there is a possibility of disagreement.

The flexibility option F measures the expected loss in NPV of the investment when disagreement leads to a veto by outsiders. From (4) we see that the flexibility option derives its value from states in which the insider has a favorable assessment, $x \in[S, \infty)$, and wishes to invest, while outsiders have an unfavorable assessment, $y \in(-\infty, S)$, and wish not to invest.

To analyze the properties of the value of the flexibility option, we assume that $q(x, y)$ is bivariate normal, with correlation $\rho \in[-1,1]$ between $\mathrm{x}$ and $\mathrm{y}$. One benefit of this is that the correlation between two normal random variables uniquely defines their joint distribution. In the more general case, one would have to work with the conditional probabilities of events rather than correlation ${ }^{7}$, which would make the comparative statics analysis of the properties of $\mathrm{F}$ rather difficult. Thus, we assume

\footnotetext{
${ }^{7}$ See Schweizer and Wolff (1981), for example.
} 


$$
\begin{gathered}
\mathrm{q}(\mathrm{x}, \mathrm{y} \mid \rho) \\
=\left\{\left[\frac{1}{2 \pi \sigma_{x} \sigma_{y} \sqrt{1-\rho^{2}}}\right] \times \exp \left\{-\frac{1}{2\left[1-\rho^{2}\right]}\left[\left(\frac{\mathrm{x}-\mu_{\mathrm{x}}}{\sigma_{\mathrm{x}}}\right)^{2}-2 \rho\left(\frac{\mathrm{x}-\mu_{\mathrm{x}}}{\sigma_{\mathrm{x}}}\right)\left(\frac{\mathrm{y}-\mu_{\mathrm{y}}}{\sigma_{\mathrm{y}}}\right)+\left(\frac{\mathrm{y}-\mu_{\mathrm{y}}}{\sigma_{\mathrm{y}}}\right)^{2}\right]\right\}\right\}
\end{gathered}
$$

where $\mu_{\mathrm{x}}$ and $\sigma_{\mathrm{x}}^{2}$ are the mean and variance of $\mathrm{x}$, related to its marginal density $\mathrm{g}(\mathrm{x})$, and $\mu_{\mathrm{y}}$ and $\sigma_{\mathrm{y}}^{2}$ are the mean and variance of $\mathrm{y}$, related to its marginal density $\mathrm{h}(\mathrm{y})$. Because we do not want to assume that the insider is any more optimistic or pessimistic than outsiders or any different in (over)confidence, we will assume that $\mu_{x}=\mu_{y}$, and $\sigma_{x}=\sigma_{y}{ }^{8}$ Further, we will assume that, in an expected value sense, the option to invest is "in the money" at $\mathrm{t}=0$, i.e.,

$$
\mu_{\mathrm{x}}=\mu_{\mathrm{y}}>\mathrm{S} \text {. }
$$

We can now state our first result.

Theorem 1: The value of the flexibility option, F, is strictly decreasing in $\rho$, the correlation between $\mathrm{x}$ and $\mathrm{y}$ for all $\rho \in(-1,1)$.

This theorem is intuitive. The flexibility option is most valuable to the insider when the insider and outsiders are most likely to disagree. This is the case when the correlation between $\mathrm{x}$ and $y$ is the lowest. The next result focuses on the effect of the variances of $x$ and $y$ on the value of the flexibility option.

Theorem 2: The value of the flexibility option, $\mathrm{F}$, is strictly increasing in $\sigma_{\mathrm{x}}^{2}$, the variance of $\mathrm{x}$, and also in $\sigma_{\mathrm{y}}^{2}$, the variance of $\mathrm{y}$.

The intuition behind this theorem is as follows. $\mathrm{F}$ is increasing in the variance of $\mathrm{x}$ for the usual reason that the value of a call option increases with the variance in the value of the underlying asset. As for the variance of y, note that y does not directly enter the integrand in (4)

\footnotetext{
${ }^{8}$ To be technically precise, we assume these equalities hold at the points at which we examine the relationship of $\mathrm{F}$ to changes in any variables.
} 
except through the density function $\mathrm{q}(\mathrm{x}, \mathrm{y})$. Intuitively, therefore, we can focus on what a higher $\sigma_{\mathrm{y}}^{2}$ does to the probability that $\mathrm{y}<\mathrm{S}$. Because $\mathrm{S}<\mu_{\mathrm{y}}$ and the marginal density of $\mathrm{y}$ is normal, an increase in the variance of $y$ increases the probability that $y<S$. Consequently, F increases.

Our next result analyzes how the means of $\mathrm{x}$ and $\mathrm{y}$ affect $\mathrm{F}$.

Theorem 3: The value of the flexibility option, $\mathrm{F}$, is increasing in $\mu_{\mathrm{x}}$ the mean of $\mathrm{x}$, and decreasing in $\mu_{\mathrm{y}}$, the mean of $\mathrm{y}$.

The intuition is that as the mean of $\mathrm{x}$ increases, the insider's assessment of the future value of the investment opportunity also increases, so the value of being able to invest even in the face of disagreement is augmented as well. As for the mean of y, an increase in this variable means that outsiders are more likely to receive a signal that the investment opportunity is good, which diminishes the likelihood of disagreement for any fixed correlation coefficient; here the asymmetric nature of flexibility-the outsiders' signal $\mathrm{y}$ is irrelevant when $\mathrm{x}<\mathrm{S}$-plays a role. ${ }^{9}$ Hence, the value of the flexibility option declines.

Thus far we have dealt with flexibility as a binary variable, in that either the insider has it (thereby availing of its full value F, with the value of investment being $A+F$ ), or he does not (in which case the value of the investment is merely A). In reality, the insider's flexibility is much more likely to be between these two extremes. There may be instances in which the insider will be able to overcome disagreement by outsiders and instances in which outsiders will successfully veto the decision. Thus, it may be more reasonable to depict flexibility as a continuous variable, say a probability $\eta \in[0,1]$, which represents the likelihood that the insider will be able to implement his decision even when there is disagreement. We will henceforth refer to $\eta$ as the "flexibility probability". In our analysis, we take $\eta$ as exogenously given. In practice, it is likely

\footnotetext{
${ }^{9}$ Without this asymmetry, an increase in the mean of y would decrease the likelihood of disagreement conditional on $\mathrm{x} \geq \mathrm{S}$ and increase this likelihood conditional on $\mathrm{x}<\mathrm{S}$.
} 
to be affected by a host of factors, such as the type of contract between the insider and outsiders, the reputation of the insider based on past decisions and so on.

We can then write (2) as:

$$
\mathrm{E}(\mathrm{V} \mid \eta)=\mathrm{A}+\eta \mathrm{F}
$$

where A and F are defined in (3) and (4) respectively. The outsiders' assessment of the value of the investment depends on the decision of the insider, and equals:

$$
\mathrm{E}\left(\mathrm{V}_{\mathrm{o}} \mid \eta\right)=\mathrm{A}_{\mathrm{o}}-\eta \mathrm{F}_{\mathrm{o}}
$$

where

$$
\begin{aligned}
& A_{o} \equiv \int_{s}^{\infty} \int_{s}^{\infty}[y-S] q(x, y \mid \rho) d x d y \\
& F_{o}=\int_{-\infty s}^{s} \int_{s}^{\infty}[S-y] q(x, y \mid \rho) d x d y
\end{aligned}
$$

where $A_{o}$ is the outsiders' assessment of the value of the investment in the case of agreement and $F_{o}$ is the cost of the flexibility option to outsiders. The following result is now immediate.

Theorem 4: An increase in the flexibility probability $\eta$ leads to a strict increase in the value of the investment opportunity to the insider (i.e., $\partial \mathrm{E}(\mathrm{V} \mid \eta) / \partial \eta>0$ ) and a strict decrease in the value of the investment opportunity to outsiders (i.e., $\left.\partial \mathrm{E}\left(\mathrm{V}_{\mathrm{o}} \mid \eta\right) / \partial \eta<0\right)$.

The intuition is that an increase in $\eta$ means a higher probability that the insider will prevail when there is disagreement. This increases the expected value of the investment opportunity, as assessed by the insider. The opposite is true for outsiders. This theorem highlights the tension that flexibility creates between the value of flexibility to the insider and its cost to outsiders who may disagree with the insider. In many applications, we will be maximizing the insider's objective function, $\mathrm{E}(\mathrm{V} \mid \eta)$, subject to an ex ante participation constraint for outsiders. Consequently, the "cost" of flexibility to outsiders is something that 
will, in equilibrium, be passed on to the insider ex ante. This means that the insider will have to trade off the ex post benefit of flexibility against the ex ante cost of "compensating" outsiders for this flexibility. This tradeoff will be an important aspect of the applications discussed next.

\section{APPLICATIONS TO FINANCIAL DECISIONS}

In this section we discuss four applications of flexibility to financial contracting and decisions. The first application is the entrepreneur's problem of what kind of contractual arrangement to use in raising venture capital. The second is a corporation's problem of designing securities and deciding when to issue which security. The third application involves the role of collateral in lending. The fourth is capital budgeting.

For these applications, it is useful to think in terms of the total value of the project (or the firm) rather than just the NPV. That is, think of $S$ as the value of assets (perhaps cash) that the firm has currently, and $\mathrm{x}$ (or $\mathrm{y}$ ) as the signal about the value of the new opportunity that is mutually exclusive with the assets in place. That is, if one takes advantage of the new opportunity, then one invests $\mathrm{S}$ and the value of the firm becomes $\mathrm{x}$ as viewed by the insider and $\mathrm{y}$ as viewed by outsiders. If one passes up the new opportunity, the value of the firm is S. Let us designate the total firm value as TV, so that the value to the insider equals:

$$
\mathrm{E}(\mathrm{TV} \mid \eta)=\mathrm{A}+\eta \mathrm{F}+\mathrm{S}
$$

and the value to the outsider is:

$$
\mathrm{E}\left(\mathrm{TV}_{\mathrm{o}} \mid \eta\right)=\mathrm{A}_{\mathrm{o}}-\eta \mathrm{F}_{\mathrm{o}}+\mathrm{S}
$$

\subsection{The Entrepreneur's Financing Problem}

Consider the following situation. At date $\mathrm{t}=0$, an entrepreneur (insider) raises funds in the amount of \$I from venture capitalists (VCs) whom we shall view as outsiders. At this time, a contract is negotiated between the entrepreneur and the VCs which specifies: (a) how much 
equity ownership, $\alpha \in(0,1)$, the $\mathrm{VCs}$ receive in exchange for providing $\$ \mathrm{I}^{10}$ and (b) the flexibility probability $\eta$. The entrepreneur operates his business by investing $\$ \mathrm{I}$ to hire employees and acquire office space, furniture and computers. There is no uncertainty about this activity. However, at some future date, say $\mathrm{t}=1$, a new investment opportunity will arise whose value will be $\mathrm{x}$ as assessed by the entrepreneur and $\mathrm{y}$ as assessed by the VCs. At this point, I is a sunk cost and the firm's assets in place are worth S. Investing in this opportunity will tie up all of the assets in place. The flexibility probability $\eta$ will determine whether the entrepreneur is able to take advantage of this opportunity if the VCs object. Let R represent the VCs' reservation rate of return for providing funds to the entrepreneur. $\mathrm{R}$ may vary depending on whether there is a scarcity of investment funds relative to the number of entrepreneurial projects in the economy or a scarcity of projects relative to the available capital.

At $\mathrm{t}=0$, the entrepreneur's problem can be written as

$$
\operatorname{Max}_{\eta \in[0,1]}\{\mathrm{A}+\eta \mathrm{F}+\mathrm{S}\}\{1-\alpha\}
$$

subject to $\alpha\left\{\mathrm{A}_{\mathrm{o}}-\eta \mathrm{F}_{\mathrm{o}}+\mathrm{S}\right\} \geq \mathrm{I}[1+\mathrm{R}]$

The following result is immediate.

Lemma 1: The VCs'ownership fraction $\alpha$ is increasing in the flexibility probability $\eta$. Moreover, for any fixed $\alpha$, an increase in the VCs' reservation return R decreases $\eta$.

This simple result highlights some interesting points. First, the entrepreneur faces a tradeoff between flexibility and the cost of capital. As he seeks higher flexibility, the ownership he has to surrender to the VCs goes up, i.e., the cost of capital increases. Thus, the "cost" of the entrepreneur's flexibility that the VCs absorb ex post is borne ex ante by the entrepreneur. Moreover, when $\mathrm{R}$ is high, say because there is a paucity of investment capital relative to the

\footnotetext{
${ }^{10}$ Numerous papers in the venture capital literature (e.g. Gompers and Lerner $\left.(1998,1999)\right)$ have shown that venture capital is predominated by equity contracts, so we take that as a given here.
} 
projects seeking funding, the entrepreneur will choose to accept less flexibility for any chosen share of ownership he surrenders to the VCs. That is, entrepreneurs will tend to finance with less restrictive contracts during funding booms and with more restrictive contracts during funding contractions, for any fixed ownership share given to VCs. ${ }^{11}$

As is well known, VCs often finance entrepreneurs using contracts that restrict the entrepreneur's flexibility significantly by giving the VCs the ability to intervene and exercise control that is disproportionate relative to the ownership share held by the VCs (see Admati and Pfleiderer (1994), Chan, Siegel and Thakor (1990), and Gompers and Lerner (1998,1999)). That is, these contracts appear to explicitly separate financial ownership from flexibility.

It is intuitive to expect that the expected value of the project the entrepreneur seeks to finance and the correlation between the entrepreneur's and VCs' opinions will affect both the value and cost of flexibility to the entrepreneur. The following results can now be proved.

Theorem 5: The cost of the insider's flexibility option to outsiders, $F_{o}$, is increasing in $\mu_{x}$, the expected value of $x$, and decreasing in $\mu_{y}$, the expected value of $y . F_{o}$ is decreasing in $\rho$, the correlation between $\mathrm{x}$ and $\mathrm{y}$ for all $\rho \in(-1,1)$.

The intuition is that an increase in $\mu_{\mathrm{x}}$ makes it more likely that the insider will exploit the investment opportunity without making it more likely that outsiders will want it exploited. This increases the expected cost outsiders perceive related to the insider investing in a state in which outsiders view the investment as a bad idea. An increase in $\mu_{\mathrm{y}}$ makes the investment opportunity more valuable to outsiders and hence lowers the cost of the flexibility option to them. This theorem thus exposes an interesting tension for the entrepreneur as the assessed expected value of the project as viewed by the entrepreneur $\left(\mu_{\mathrm{x}}\right)$ increases. On the one hand, the

\footnotetext{
${ }^{11}$ For a paper that empirically examines the consequences of post-funding disagreement between the VC and the entrepreneur, see Higashide and Birley (2002).
} 
value of flexibility to the entrepreneur, F, increases (Theorem 3), so he would like greater flexibility. On the other hand, the cost of this flexibility, $F_{o}$, also increases, which would pull the entrepreneur in the direction of seeking less flexibility. The net effect will depend on how F and $F_{o}$ change in relative terms as $\mu_{x}$ increases. The intuition behind why $F_{o}$ is decreasing in $\rho$ is similar to that for Theorem 1. As the opinions of the insider and outsider become more correlated, outsiders perceive a lower cost of giving the insider flexibility. We now examine the impact of uncertainty on $\mathrm{F}_{\mathrm{o}}$.

Lemma 2: The cost of the insider's flexibility option to outsiders, $F_{o}$, is decreasing in $\sigma_{x}^{2}$, the variance of $\mathrm{x}$.

The intuition is as follows. Because the density function of $\mathrm{x}$ is symmetric around its mean, and $\mathrm{S}<\mu_{\mathrm{x}}$, an increase in the variance of $\mathrm{x}$ decreases the probability that $\mathrm{x}>\mathrm{S}$. Thus, outsiders perceive a lower probability that the insider will exercise the flexibility option, which reduces $\mathrm{F}_{\mathrm{o}}$.

Theorem 6: As the value of the new investment opportunity to the entrepreneur becomes more uncertain ( $\sigma_{x}^{2}$ increases), the optimal degree of flexibility $(\eta)$ he seeks also increases, as does his expected payoff.

The intuition is that an increase in $\sigma_{x}^{2}$ increases $F$, the value of the flexibility option to the entrepreneur (Theorem 2), and decreases $F_{0}$, the cost of the flexibility option to the VCs (Lemma 2). From (13) and (14) we know then that an increase in $\sigma_{x}^{2}$ increases the marginal value of flexibility to the entrepreneur and decreases the marginal cost of flexibility to the VCs. Thus, an entrepreneur who brings a more risky project for funding obtains greater flexibility.

\subsection{Design and Issuance of Financial Securities}

The problem analyzed in the previous subsection can be generalized to that of designing 
financial securities and deciding which to issue. Boot, Greenbaum and Thakor (1993) pointed out that there is a choice between discretionary and legally-binding financial contracts. ${ }^{12}$ In their model, discretion has to do with whether a party to the contract can choose to not honor the contract in some states of the world. By contrast, flexibility in our analysis is not about declining to honor the terms of a contract. Rather, it is one party having the ability to do what it perceives is optimal, in the face of divergent beliefs about the optimal course of action.

We believe that, in addition to specifying a particular sharing rule for financial payoffs, every financial contract stipulates a degree of flexibility. Equity is a more flexible contract than debt partly because it gives management the flexibility to pay whatever dividends it chooses, whereas debt contractually obligates the firm to make periodic interest payments. Similarly, from the borrower's standpoint, bank debt is a more flexible contract than public debt because bank debt is typically considered easier to renegotiate (Berlin and Mester (1992)). Since different financial securities provide varying degrees of flexibility to the issuer, the choice of which security to raise financing with will also be driven by how much flexibility the issuer needs at a given point in time and the tradeoff between the value of flexibility and the impact of flexibility on the cost of capital for that security. Our theory predicts that securities with greater flexibility will carry a higher cost of capital, controlling for priority/seniority, even if there are no tax-treatment differences. Thus, when a firm anticipates having access to future investment opportunities whose perceived value is relatively difficult to estimate (high $\sigma_{x}^{2}$ ) and subject to disagreement, it will value its flexibility option highly and will perceive a "pecking order" of securities, with equity being the most attractive, followed by preferred stock, bank debt and public debt. Contrast this with the asymmetric-information-based pecking order derived by

\footnotetext{
${ }^{12}$ More specifically, in Boot, Greenbaum and Thakor (1993) discretionary contracts are viewed as "illusory promises" that are honored only at the discretion of one of the two contracting parties, and incentives to honor such promises are driven by the tradeoff between the financial costs and reputational benefits of honoring the contract.
} 
Myers and Majluf (1984) in which equity is at the bottom of the pecking order. According to our analysis, the firm may choose the Myers and Majluf (1984) pecking order when it anticipates future investment opportunities with relatively low variance, and values its flexibility option less highly. $^{13}$

\subsection{The Role of Collateral in Lending}

Bank loans are either secured or unsecured. While secured loans are more common than unsecured loans, banks routinely make unsecured loans. Collateral lowers the cost of debt financing (see Rajan and Winton (1995)), so it is somewhat puzzling why all loans are not secured. That is, what exactly is the cost the borrower perceives in pledging an asset as collateral?

Our theory suggests that the cost may be rooted in the loss of flexibility that accompanies the pledging of an asset as collateral. While the asset continues to rest with the borrower as long as there is no default, its deployment as collateral restricts how it can be used, limiting the borrower's flexibility. Thus, as in the previous applications, the borrower trades off the cost of borrowing against the cost of losing flexibility. Secured loans will be preferred when the perceived cost of losing flexibility is relatively low, and unsecured loans will be preferred when this cost is relatively high.

\subsection{Capital Budgeting: Rules Versus Discretion}

Most firms have explicit rules that govern their capital budgeting. These rules often require forecasts of future cash flows, calculations of NPV, etc. Only projects that satisfy certain prespecified criteria can be approved. Other firms have "toll gates" wherein resource

\footnotetext{
${ }^{13}$ It appears then that flexibility offers a new way to approach security design that is different from the risk-sharing and information-based approaches currently in vogue. See for example Allen and Gale (1994), Boot and Thakor (1993), Chowdhry, Grinblatt and Levine (2002), and Fulghieri and Lukin (2001).
} 
commitments to projects are escalated as they pass through various toll gates over time. At each toll gate, there is a set of criteria that the project must meet to receive further funding.

In our context, we can interpret the signal $y$ as the outcome of this explicit capital budgeting analysis. Thus, $\mathrm{y}$ is a signal that can be supported based on cash flow forecasts and NPV analysis, i.e., it is the signal received by the firm or outsiders (shareholders). The capital budgeting criteria stipulate that the project can be funded only if $y \geq S$.

We can interpret $x$ as the private signal of the insider (or the "internal champion") on the project. This signal may be based on the insider's intuition or "gut feel" and may not be something that the insider can support/validate based on data. The question is: how much flexibility should the firm give the insider to "break the rules" and invest in the project (when $\mathrm{x} \geq$ S) even though $y<S$ ? In other words, what should be the relative roles of rules and discretion in capital budgeting?

To address this question, we introduce a bit more structure. Let $\beta$ be the probability that the insider's intuition is correct compared to the "objective" signal y. That is, $\beta$ is the probability that the expected value of the project should be based on $x$, and $1-\beta$ is the probability that the expected value of the project should be based on $y$. Further, suppose $\beta$ varies depending on the type of the project, so we can write it as $\beta_{i}$, where $i$ represents the project's "type." Note that the insider always believes his intuition is correct, and that $x$ is the appropriate signal. That is, $\beta$ is the probability of the insider being correct from the perspective of the outsiders; $\beta$ always equals one from the insider's perspective.

We can view $\eta_{i}$ as representing the capital budgeting "culture" for project type $i$. It represents how much flexibility the insider has to supplant the "fact-based" recommendation with his own intuition for a type- $i$ project. 
Now suppose that the insider must expend some effort at a personal cost $\mathrm{W}>0$ to bring a project forward for evaluation. We will further assume that

$$
\begin{aligned}
& \mathrm{A}+\mathrm{F}-\mathrm{W}>0 \\
& \mathrm{~A}-\mathrm{W}<0 \\
& \mathrm{~A}_{\mathrm{o}}-\mathrm{F}_{\mathrm{o}}-\mathrm{W}<0 \\
& \mathrm{~A}_{\mathrm{o}}-\mathrm{W}>0
\end{aligned}
$$

This means that the insider finds it value-enhancing (positive NPV) to bring the project forward for evaluation if the flexibility probability, $\eta_{i}$, is one ((15)), but not if it is zero ((16)). Moreover, outsiders believe the project has negative NPV if the flexibility probability is one and positive NPV if the flexibility probability is zero.

These parametric restrictions are set up to create a tension between the insider and outsiders about how much flexibility to give the insider. Outsiders would like to give no flexibility at all, but then the insider will not expend $\mathrm{W}$ to bring the project forward (see (16)). In what follows, we show that the optimal degree of flexibility to give to the insider depends on $\beta_{i}$, the probability the insider is right.

Now, given (15) and (17), we know that the expected NPV of the project (as assessed by the firm or outsiders), when the insider has full flexibility, is:

$$
\beta_{i}[\mathrm{~A}+\mathrm{F}-\mathrm{W}]+\left[1-\beta_{i}\right]\left[\mathrm{A}_{\mathrm{o}}-\mathrm{F}_{\mathrm{o}}-\mathrm{W}\right]>0
$$

for $\beta_{i}$ sufficiently high. Note that $\beta_{i}$ is the probability that the insider is right, so that the NPV to the firm is $\mathrm{A}+\mathrm{F}-\mathrm{W}$, and $1-\beta_{i}$ is the probability that the objective signal is right, in which case the NPV to the firm is $A_{o}-F_{o}-W$. Let $\beta_{i}^{+}$be the critical value of $\beta_{i}$ such that the expected NPV of the project is zero if the insider has complete flexibility (i.e. $\eta=1$ ). That is,

$$
\beta_{i}^{+}[\mathrm{A}+\mathrm{F}-\mathrm{W}]+\left[1-\beta_{i}^{+}\right]\left[\mathrm{A}_{\mathrm{o}}-\mathrm{F}_{\mathrm{o}}-\mathrm{W}\right] \equiv 0
$$


Note that (19) will hold for all $\beta_{i}>\beta_{i}^{+}$.

Similarly, given (16) and (18), we know that

$$
\beta_{i}[\mathrm{~A}-\mathrm{W}]+\left[1-\beta_{i}\right]\left[\mathrm{A}_{\mathrm{o}}-\mathrm{W}\right]>0
$$

for $\beta_{i}$ low enough. Let $\beta_{i}^{-}$be the value of $\beta_{i}$ such that

$$
\beta_{\mathrm{i}}^{-}[A-W]+\left[1-\beta_{\mathrm{i}}^{-}\right]\left[A_{\mathrm{o}}-W\right] \equiv 0
$$

That is, $\beta_{i}^{-}$is the critical value of $\beta_{i}$ such that the expected NPV (as assessed by outsiders) is zero when the insider has no flexibility $\left(\eta_{i}=0\right)$. Note that $(21)$ will hold for $\beta_{i}<\beta_{i}^{-}$.

Now write the expected NPV of the project for $\eta_{i} \in[0,1]$ as

$$
\Omega\left(\eta_{i}\right) \equiv \beta_{i}\left[\mathrm{~A}+\eta_{i} \mathrm{~F}-\mathrm{W}\right]+\left[1-\beta_{i}\right]\left[\mathrm{A}_{\mathrm{o}}-\eta_{i} \mathrm{~F}_{\mathrm{o}}-\mathrm{W}\right]
$$

It is easy to see that $\partial \Omega / \partial \eta_{i}>0$ if $\beta_{i}>\mathrm{F}_{\mathrm{o}}\left[\mathrm{F}+\mathrm{F}_{\mathrm{o}}\right]^{-1}$. This condition is intuitive. The expected NPV is increasing in flexibility if the probability that the insider is right is above a cutoff, and this cutoff is higher if the cost of flexibility to outsiders, $F_{0}$, is higher. Thus, when $\beta_{\mathrm{i}}>\max \left\{\beta_{\mathrm{i}}^{+}, F_{\mathrm{o}}\left[F+F_{\mathrm{o}}\right]^{-1}\right\}$, the value-maximizing solution is to set $\eta_{i}^{*}=1$. Note that the incentive compatibility condition for the insider to bring the project forward for evaluation is

$$
\mathrm{A}+\eta_{i} \mathrm{~F}-\mathrm{W} \geq 0
$$

which will be satisfied at $\eta_{i}=\eta_{i}^{*}$ because of (15).

Consider now $\beta_{i}<\beta_{i}^{-}$. It is easy to verify that $\partial \Omega / \partial \eta_{i}<0$ if $\beta_{i}<\mathrm{F}_{\mathrm{o}}\left[\mathrm{F}+\mathrm{F}_{\mathrm{o}}\right]^{-1}$. Thus, when $\beta_{i}<\min \left\{\beta_{i}^{-}, \mathrm{F}_{\mathrm{o}}\left[\mathrm{F}+\mathrm{F}_{\mathrm{o}}\right]^{-1}\right\}$, the value-maximizing solution is to set $\eta$ as low as possible while still satisfying (24). Let $\hat{\eta}_{i}$ be the value of $\eta_{i}$ for which (24) holds as an equality. Then it is value-maximizing to set $\eta_{i}=\hat{\eta}_{i}>0$ if

$$
\Omega\left(\hat{\eta}_{i}\right) \geq 0
$$


This discussion leads to the following result.

Theorem 7: Assume that (15) - (18) hold. Then, for a sufficiently high value of $\beta_{i}$, the probability that the insider's intuition is correct, it is value-maximizing to give the insider complete flexibility $\left(\eta_{i}^{*}=1\right)$. For a sufficiently low value of the probability that the insider's intuition is correct, it is value-maximizing to give the insider partial but positive flexibility $\left(\hat{\eta}_{i} \in(0,1)\right)$ if the expected project $\operatorname{NPV}\left(\Omega\left(\eta_{\mathrm{i}}\right)\right)$ is sufficiently high.

This theorem has numerous implications. First, discretion will be allowed to supplant rules when the insider's intuition is very likely to dominate data-based analysis. This will tend to be true for innovative projects that are so different from what the firm has done in the past that historical data are simply not very reliable compared to the intuitive judgment of a sufficiently skilled decisionmaker. Examples may be new technologies (such as cloning) or new business designs (such as Internet auctions).

Second, it may be worth giving the insider some flexibility even when the firm believes that data-driven analysis dominates the insider's intuition. This is because sufficient incentives must be provided to the insider to bring the project forward for evaluation at a personal cost. But in this case, flexibility is value-enhancing only if the project is sufficiently valuable. Otherwise, the firm is better off not giving the insider any flexibility.

This analysis is consistent with capital budgeting practice. Most firms have formal capital budgeting systems with rules for project approval. However, exceptions are sometimes made for potentially highly-valuable "strategic" or "innovative" projects.

\section{OTHER APPLICATIONS OF FLEXIBILITY}

In this section we consider four additional applications of flexibility. The first is the introduction of flexibility into the principal-agent problem, the second is the interpretation of 
organizational power as flexibility, the third is examining organizational conformity in the context of flexibility, and the fourth is the choice of public versus private ownership.

\subsection{Flexibility and the Principal-Agent Model}

Suppose the principal is the outsider and the agent is the insider. The principal is risk neutral and the agent is risk averse. The agent's reservation utility is $\bar{U}$ and he is compensated by a contract of the form: $\phi(\mathrm{z})$, where $\mathrm{z}$ is the terminal output, which is realized and commonly observed at $\mathrm{t}=2$. The time line is as follows. At $\mathrm{t}=0$, the principal gives the agent the contract $\phi(\mathrm{z})$. After that, the agent chooses effort $\omega$ at $t=0$. The choice of effort affects the distribution of the terminal output $\mathrm{z}$. At $\mathrm{t}=1$, the agent sees the terminal output as $\mathrm{x}$ and the principal sees it as $y$. We will assume that, viewed at $t=0$, an increase in $\omega$ shifts $Q(x, y \mid \omega)$, the cumulative distribution associated with $\mathrm{q}(\bullet, \bullet \mid \omega)$, in the sense of first-order stochastic dominance.

The key decision about the project whose terminal output is affected by $\omega$ has to be made at $\mathrm{t}=1$. The project needs an investment of $\mathrm{S}$ at $\mathrm{t}=1$ to yield its payoff of $\mathrm{z}$ at $\mathrm{t}=2$. If $\mathrm{x} \geq \mathrm{S}$, the agent would like to invest in the project, whereas the principal would like to invest in it only if $y \geq \mathrm{S}$. Assume, as in the basic model, that the investment decision is delegated to the agent and hence $x \geq S$ is a necessary condition for investment in the project to occur at $t=1$. Let $\eta$ be the flexibility probability as in our basic model.

Define

$$
\begin{aligned}
& A_{o}(\omega) \equiv \int_{S S}^{\infty} \int_{S}^{\infty}[y-S] q(x, y \mid \omega, \rho) d x d y \\
& F_{0}(\omega) \equiv \int_{-\infty}^{S} \int_{S}^{\infty}[S-y] q(x, y \mid \omega, \rho) d x d y
\end{aligned}
$$


where, as in our previous analysis, $\mathrm{A}_{0}$ is the principal's (outsider's) assessment of the project value when there is agreement with the agent (insider) and $\mathrm{F}_{0}$ is the principal's assessment of the cost of the flexibility option.

In what follows, the intuitive discussion is greatly simplified by assuming that $\phi(\mathrm{z})=\alpha \times[\mathrm{NPV}$ of the project commonlyobserved at $\mathrm{t}=2]$. That is, the agent is simply paid some fraction, $\alpha \in(0,1)$, of the project NPV. For the points we make below, this is a harmless assumption.

The agent's utility over wealth is $\mathrm{U}(\bullet)$ and his disutility over effort is $\mathrm{W}(\omega)$, where $\mathrm{U}^{\prime}(\bullet)>0, \mathrm{U}^{\prime \prime}(\bullet)<0$, and $\mathrm{W}^{\prime}(\bullet)>0$, so we can write

$$
E(U \mid \alpha, \eta) \equiv \int_{S}^{\infty} \int_{S}^{\infty} U(\alpha[x-S]) q(x, y \mid \omega, \rho) d x d y+\eta \int_{-\infty S}^{S} \int_{S}^{\infty} U(\alpha[x-S]) q(x, y \mid \omega, \rho) d x d y-W(\omega)
$$

as the agent's expected utility. Then, the principal's problem can be stated as:

$$
\underset{(\alpha, \eta)=[0,1] \times[0,1]}{\operatorname{Max}}[1-\alpha]\left[A_{\mathrm{o}}(\omega)-\eta F_{\mathrm{o}}(\omega)\right]
$$

subject to

$$
\begin{aligned}
& \mathrm{E}(\mathrm{U} \mid \alpha, \eta)=\overline{\mathrm{U}} \\
& \omega \in \underset{\omega \in \Omega}{\operatorname{argmax}} \mathrm{E}(\mathrm{U} \mid \alpha, \eta)
\end{aligned}
$$

where $\Omega$ is a compact set from which the agent chooses $\omega$.

Even without solving this problem explicitly, some of the tradeoffs faced by the principal become apparent. The most important tradeoff is between the direct loss in project NPV and the indirect gain in value by giving the agent flexibility $(\eta)$. The direct loss in project NPV to the principal is measured by $\eta \mathrm{F}_{0}(\omega)$, and it is strictly increasing in $\eta$, holding $\alpha$ and $\omega$ fixed. The indirect gain in value comes from two sources. First, since $\partial \mathrm{E}(\mathrm{U}(\alpha, \eta)) / \partial \eta>0$, satisfying the agent's participation constraint (30) becomes less expensive to the principal as $\eta$ increases. That 
is, (30) can be satisfied with a lower $\alpha$ if $\eta$ is increased. Second, the principal can also incent the agent to choose the desired effort, say $\omega^{*}$, with a lower $\alpha$ if $\eta$ is increased (see the incentive compatibility constraint (31)). Thus, the principal trades off $\alpha$ against $\eta$ in the design of the optimal contract.

The existing principal-agent literature has emphasized the key tradeoff between risk sharing and effort incentives in optimal (second-best) incentive contract design. Our discussion highlights another key tradeoff, which is between the principal's desire to maximize his expected payoff ignoring the agent's incentive constraint—which would dictate setting $\eta=0$ and giving the agent no flexibility—and the need to motivate the agent appropriately by giving him some flexibility. That is, the flexibility tradeoff for the principal is between the expected cost of flexibility (which increases with $\eta$ ) and its incentive benefit (which also increases with $\eta) .{ }^{14}$ This may shed further light on the empirical finding that the relationship between risk and incentives in compensation contracts is positive, in contrast to the negative relationship predicted by the standard agency model (see Prendergast (2002)).

We believe that the degree of flexibility given to the agent is an important aspect of contract design, even when the principal may believe that flexibility dissipates value in and of itself. It would be interesting to explore different aspects of the principal-agent problem when flexibility is a consideration. New perspective may emerge about economic interpretations of "soft" concepts like "empowerment" in organizations. Moreover, flexibility may provide an alternative way to think about the design of political institutions and the related literature on "choosing how to choose". In that literature, the issue is the determination of the socially-optimal

\footnotetext{
${ }^{14}$ It is easy to see that if the incentive constraint (31) was not a concern, the optimal solution would be to set $\eta=0$ and give the agent a fixed wage, so that any disagreement between the agent and the principal about project value becomes irrelevant.
} 
checks and balances for elected leaders, which then affects how much unchecked power leaders have. $^{15}$

\subsection{Power in Organizations}

A simple interpretation of flexibility is that it represents power in an organizational setting. That is, flexibility is "real authority" in the sense of Aghion and Tirole (1997). If we interpret $\mathrm{y}$ as the recommendation based on the rules and procedures of the organization, then power is the ability to make decisions outside the boundaries defined by organizational rules. If we interpret $\mathrm{y}$ as the consensus opinion of those other than the decisionmaker, then power is the ability to do something that others in the organization disagree with.

Interpreted this way, power is typically an inverted pyramid in an organization - it increases as you move up the hierarchy. Why? Our theory of flexibility offers a possible explanation. Suppose that there are two types of insiders: competent and incompetent. Competent insiders have good intuition in that $\mathrm{x}$ is a more precise indicator of the eventual outcome than $\mathrm{y}$. Incompetent insiders have bad intuition in that $\mathrm{x}$ is a less precise indicator of the eventual outcome than y. Over time, insiders will develop reputations for competence and a sorting will occur based on these reputations. Those judged to be more competent will get promoted over those judged to be less competent. An insider's human capital will increase every time he makes a decision based on $\mathrm{x}$ (his intuitive judgment) that conflicts with $\mathrm{y}$ (the rules) and the outcome reveals ex post he was right. Those at the top of the organizational hierarchy will have the best reputations for their intuitive judgment or competence. Consequently, they will also be given the most power or flexibility to "break the rules."

This perspective reveals that the sorting of individuals based on perceived competence

\footnotetext{
${ }^{15}$ For example, Aghion and Bolton (1997), Maskin and Tirole (2001), and particularly Aghion, Alesina and Irebbi (2002), where the tradeoff is between the increased likelihood of good reforms being blocked if leaders are given too little power and the increased likelihood of expropriation if they are given too little power. Our flexibility perspective would say that the amount of power given to the leader may affect both the types of politicians willing to run for office as well as the effort expended by the leader once in office.
} 
will be the slowest in organizations that are the most "rule-bound", i.e., where individuals have the least flexibility. Thus, Microsoft or Cisco should sort out individuals based on intuitive judgment (or leadership capability) faster than a government bureaucracy.

One could also think of our analysis as endogenizing the private benefit of control, since "control" can be interpreted as the possession of power or flexibility. However, it is important to note that the insider in our analysis values control not because of any perceived personal benefit at the expense of firm value. Rather, control is valued because it provides flexibility to maximize firm value.

\subsection{Conformity in Organizations}

There is now a substantial literature that seeks to explain why people tend to agree too much, especially with their superiors (see, for example, Prendergast (1993) and the references therein). Considerations of flexibility provide a simple explanation.

There are two ways to understand conformity. If, as in the previous subsection, there is an organizational sorting so that those with better intuition are more likely to be promoted, then a subordinate will wish to agree with his boss, even if his boss is breaking the rules the subordinate believes in, simply because the boss is likely to be right. Alternatively, the boss may have an innate preference for flexibility which may be manifested in a negative utility associated with not being able to make the decision she wants because others disagree. The subordinate may therefore agree with the boss when others disagree, in order to increase the probability the boss will prevail (i.e., contribute to an increase in $\eta$ ).

\subsection{Private Versus Public Ownership}

Flexibility is also likely to be a consideration in the firm's decision of whether to be publicly or privately owned. When a firm is publicly owned, it cannot choose the degree of flexibility ( $\eta$ ) associated with equity. This is likely to be determined by the firm's past financial 
performance and the reputation of its senior management. The better the firm's past performance and the more reputable its management, the higher is $\eta$ likely to be because the Board of Directors and institutional investors will tend to provide management more "elbow room" in this case, giving it the benefit of the doubt when there is disagreement. Celebrated CEOs like Jack Welch, Bill Gates and Michael Eisner have apparently enjoyed greater flexibility than their counterparts in firms that did not perform as well over comparable time periods.

By contrast, with private equity, management can choose financiers who are willing to provide it with the desired flexibility. But this greater flexibility often looks like a Faustian bargain since private equity financiers typically have a higher ability to replace management. That is, management can choose its desired tradeoff between flexibility on the one hand and the cost of equity and personal risk on the other, opting for greater flexibility possibly by accepting a higher equity cost of capital and a higher probability of being fired. For the financiers, the lower diversification and liquidity that accompany private ownership are traded off against the higher expected payoff they perceive from investing in a firm whose management they have confidence in and can more easily replace if that confidence evaporates. Private financiers usually play a different role compared to the corporate governance imposed by public shareholders who are more distant and have less control in firing management; they can only hamper management in the case of disagreement. Thus, a key distinction between public and private ownership may be that the degree of flexibility in the former is "market-determined", whereas it may be a choice variable in the latter. We would expect intuitively that publicly-traded firms with better past performance and more reputable CEOs would enjoy both higher degrees of flexibility and higher stock prices. Conversely, low stock prices may indicate a lack of investor confidence in the CEO and a lower degree of flexibility for the CEO. This will diminish the benefits the CEO perceives with public ownership, and will increase the relative attractiveness of private ownership when 
the firm's stock price is low.

An example of this is provided by the recent experience of small publicly-owned companies in the European Union that have been viewed as facing a somewhat hostile environment in the financial markets that has adversely affected their strategic and operational flexibility. For example, an insider in one of these companies stated, "With equity markets consistently ignoring the merits of small and mid-cap corporates, the option to exit the public market and go private is becoming more and more alluring."16 This is consistent with the implications of our theory which suggests that when the flexibility associated with public equity is sufficiently low, it might become more attractive for management or (possibly hostile) bidders to take the firm private and "manage" its degree of flexibility.

\section{CONCLUSION}

The goal of this paper has been to provide economic content to "flexibility." The starting point of our analysis has been the premise that different people may perceive the same reality in different ways, so that two agents observing the same information may disagree on the optimal course of action suggested by that information. Faced with such disagreement, "flexibility" for the decisionmaker is defined as the ability to make the decision he thinks is best even though others view it as a mistake.

We have shown that flexibility is analogous to an option whose value increases with the potential for disagreement. This perspective on flexibility paves the way for examining a variety of different applications of the concept. We discuss: (i) how flexibility considerations can affect the terms and mix of external financing chosen by an entrepreneur, (ii) how flexibility can be used to analyze a firm's security issuance decision, (iii) how flexibility can determine the choice between secured and unsecured loans, (iv) how the use of rules versus discretion in capital

\footnotetext{
${ }^{16}$ See Corporate Finance Magazine, June 2001, pp. 28-31.
} 
budgeting can be understood using flexibility, (v) how flexibility can be introduced in principalagent models as an added dimension of contract design, (vi) how flexibility sheds light on our understanding of power and conformity in organizations, and (vii) the firm's choice between private and public ownership.

Our initial exploration of flexibility suggests that there is a rich agenda for future research. One possibility is to dive more deeply into the topics we have discussed as applications, and think of other applications of flexibility. 


\section{Appendix}

Proof of Theorem 1: The value of F is given by (4).

Now define $u \equiv \frac{x-\mu_{x}}{\sigma_{x}}, w \equiv \frac{y-\mu_{y}}{\sigma_{y}}$

Substituting (A-1) in (4) and writing $\mathrm{q}(\mathrm{x}, \mathrm{y} \mid \rho)$ as a bivariate normal density using (5), we can express (4) as

$\left.\mathrm{F}=\int_{-\infty}^{\left[S-\mu_{\mathrm{y}}\right] / \sigma_{\mathrm{y}}} \int_{\left[S-\mu_{\mathrm{x}}\right] / \sigma_{\mathrm{x}}}^{\infty}\left[\mathrm{u} \sigma_{\mathrm{x}}+\mu_{\mathrm{x}}-\mathrm{S}\right] \hat{\mathrm{q}}(\mathrm{u}, \mathrm{w}) \mathrm{dudw}\right]$

where

$\hat{\mathrm{q}}(\mathrm{u}, \mathrm{w}) \equiv \frac{\exp \left\{-\left[1 / 2\left[1-\rho^{2}\right]\right]\left[\mathrm{u}^{2}-2 \rho \mathrm{uw}+\mathrm{w}^{2}\right]\right\}}{2 \pi \sqrt{1-\rho^{2}}}$

which upon simplification yields:

$\hat{\mathrm{q}}(\mathrm{u}, \mathrm{w}) \equiv \frac{\exp \left\{-\left[1 / 2\left[1-\rho^{2}\right]\right]\left[(\mathrm{w}-\rho \mathrm{u})^{2}+\left(1-\rho^{2}\right) \mathrm{u}^{2}\right]\right\}}{2 \pi \sqrt{1-\rho^{2}}}$

Now substitute

$\alpha \equiv \frac{\mathrm{w}-\rho \mathrm{u}}{\sqrt{1-\rho^{2}}}$ and $\mathrm{d} \alpha \equiv \frac{\mathrm{dw}}{\sqrt{1-\rho^{2}}}$ in $(\mathrm{A}-2)$

to write:

$\mathrm{F}=\int_{\left[\mathrm{S}-\mu_{\mathrm{x}}\right] / \sigma_{\mathrm{x}}}^{\infty}\left[\int_{-\infty}^{\hat{\mathbf{J}}_{(\rho, \mathrm{u})}} \frac{\mathrm{e}^{-\alpha^{2} / 2}}{\sqrt{2 \pi}} \mathrm{d} \alpha\right]\left[\mathrm{u} \sigma_{\mathrm{x}}+\mu_{\mathrm{x}}-\mathrm{S}\right] \frac{\mathrm{e}^{-\mathrm{u}^{2} / 2}}{\sqrt{2 \pi}} \mathrm{du}$

where

$\hat{\mathbf{J}}(\rho, \mathrm{u}) \equiv \frac{\left\lfloor(S-\mu) / \sigma_{y}\right\rfloor-\rho \mathrm{u}}{\sqrt{1-\rho^{2}}}$

Also define 


$$
\hat{\mathrm{P}}(\hat{\mathrm{J}}(\rho, \mathrm{u})) \equiv \int_{-\infty}^{\hat{\mathrm{J}}(\rho, \mathrm{u})} \frac{\mathrm{e}^{-\alpha^{2} / 2}}{\sqrt{2 \pi}} \mathrm{d} \alpha
$$

Note that

$\mathrm{d} \hat{\mathrm{P}} / \partial \rho \equiv[\partial \hat{\mathrm{P}} / \partial \hat{\mathrm{J}}][\partial \hat{\mathrm{J}} / \partial \rho]$

and $\partial \hat{\mathrm{P}} / \partial \hat{\mathrm{J}}>0$.

Now,

$$
\partial \mathrm{F} / \partial \rho=\int_{\left[S-\mu_{\mathrm{x}}\right] / \sigma_{\mathrm{x}}}^{\infty}[\mathrm{d} \hat{\mathrm{P}} / \mathrm{d} \rho]\left[\mathrm{u} \sigma_{\mathrm{x}}+\mu_{\mathrm{x}}-\mathrm{S}\right] \frac{\mathrm{e}^{-\mathrm{u}^{2} / 2}}{\sqrt{2 \pi}} \mathrm{du}
$$

Since $u \sigma_{x}+\mu_{x}-S>0 \forall u$ in the range of integration, we know that the sign of the integrand in (A-7) and hence the integral itself will be the same as the sign of $d \hat{P} / d \rho$. Further, since $\partial \hat{\mathrm{P}} / \partial \hat{\mathbf{J}}>0$, the sign of $\partial \mathrm{F} / \partial \rho$ will be the same as the sign of $\partial \hat{\mathrm{J}} / \partial \rho$.

Now,

$\partial \hat{\mathbf{J}} / \partial \rho=\frac{\left[\rho\left[S-\mu_{y}\right] / \sigma_{y}\right]-\mu}{\left[1-\rho^{2}\right]^{3 / 2}}$

Since $u>\left[S-\mu_{x}\right] / \sigma_{x}=\left[S-\mu_{y}\right] / \sigma_{y}$, we see that $\partial \hat{J} / \partial \rho<0$, which means $\partial F / \partial \rho<0$.

Proof of Theorem 2: The result can be obtained by differentiating (A-4) with respect to $\sigma_{\mathrm{x}}$. Note that

$$
\begin{aligned}
\partial F / \partial \sigma_{x} & =\int_{\left[S-\mu_{x}\right] / \sigma_{x}}^{\infty} \hat{P}(\hat{J}(\rho, u)) u \frac{e^{-u^{2} / 2}}{\sqrt{2 \pi}} d u \\
& >0 .
\end{aligned}
$$

Similarly, 


$$
\begin{aligned}
\partial \mathrm{F} / \partial \sigma_{\mathrm{y}} & =\int_{\left[S-\mu_{\mathrm{x}}\right] / \sigma_{\mathrm{x}}}^{\infty}\left[\frac{\mathrm{e}^{-\hat{\mathrm{j}}^{2} / 2}}{\sqrt{2 \pi}}\left\{\frac{-\left[\mathrm{S}-\mu_{\mathrm{y}}\right]}{\sigma_{\mathrm{y}}{ }^{2} \sqrt{1-\rho^{2}}}\right\}\right] \frac{\left[\mathrm{u} \sigma_{\mathrm{x}}+\mu_{\mathrm{x}}-\mathrm{S}\right]}{\sqrt{2 \pi}} \mathrm{e}^{-\mathrm{u}^{2} / 2} \mathrm{du} \\
& >0 \text { since } \mu_{\mathrm{y}}>\mathrm{S} .
\end{aligned}
$$

Proof of Theorem 3: Differentiating (A-4) with respect to $\mu_{\mathrm{x}}$ yields:

$$
\begin{aligned}
\partial \mathrm{F} / \partial \mu_{\mathrm{x}} & =\int_{\left[\mathrm{S}-\mu_{\mathrm{x}}\right] / \sigma_{\mathrm{x}}}^{\infty} \hat{\mathrm{P}}(\hat{\mathrm{J}}(\rho, \mathrm{u})) \frac{\mathrm{e}^{-\mathrm{u}^{2} / 2}}{\sqrt{2 \pi}} \mathrm{du} \\
& >0 .
\end{aligned}
$$

Differentiating (A-4) with respect to $\mu_{\mathrm{y}}$ yields:

$$
\partial \mathrm{F} / \partial \mu_{\mathrm{y}}=\int_{\left[\mathrm{S}-\mu_{\mathrm{x}}\right] / \sigma_{\mathrm{x}}}^{\infty}\left[\mathrm{dP} / \mathrm{d} \mu_{\mathrm{y}}\right]\left[\mathrm{u} \sigma_{\mathrm{x}}+\mu_{\mathrm{x}}-\mathrm{S}\right] \frac{\mathrm{e}^{-\mathrm{u}^{2} / 2}}{\sqrt{2 \pi}} \mathrm{du}
$$

where $\mathrm{d} \hat{\mathrm{P}} / \mathrm{d} \mu_{\mathrm{y}}=[\partial \hat{\mathrm{P}} / \partial \hat{\mathrm{J}}]\left[\partial \hat{\mathrm{J}} / \partial \mu_{\mathrm{y}}\right]$, with $\partial \hat{\mathrm{P}} / \partial \hat{\mathbf{J}}>0$. Now,

$$
\mathrm{d} \hat{\mathrm{P}} / \mathrm{d} \mu_{\mathrm{y}}=\frac{\mathrm{e}^{-\hat{\mathrm{S}}^{2} / 2}}{\sqrt{2 \pi}}\left[\frac{-1}{\sigma_{\mathrm{y}} \sqrt{1-\rho^{2}}}\right]<0,
$$

which means $\partial \mathrm{F} / \partial \mu_{\mathrm{y}}<0$.

Proof of Theorem 4: Immediate upon differentiating $\mathrm{E}\left(\mathrm{V}_{1} \mid \eta\right)$ and $\mathrm{E}\left(\mathrm{V}_{\mathrm{o}} \mid \eta\right)$ in (7) and (8) respectively.

Proof of Lemma 1: Note that in equilibrium, (14) should be binding, i.e.,

$$
\alpha\left\{A_{o}-\eta F_{o}+S\right\}=I[1+R]
$$

Thus,

$$
\begin{aligned}
& {[\partial \alpha / \partial \eta]\left[A_{\mathrm{o}}-\eta F_{\mathrm{o}}+S\right]-\alpha F_{\mathrm{o}}=0} \\
& \text { or } \partial \alpha / \partial \eta=\frac{\alpha F_{\mathrm{o}}}{A_{\mathrm{o}}-\eta F_{\mathrm{o}}+S}>0
\end{aligned}
$$

Moreover, for a fixed $\alpha$, by rearranging (A-10) we get: 
$\eta=\frac{\alpha\left[A_{\mathrm{o}}+S\right]-I[1+R]}{\alpha F_{\mathrm{o}}}$

so that

$\partial \eta / \partial R=\frac{-I}{\alpha F_{\mathrm{o}}}<0$

Proof of Theorem 5: We know that $F_{o}$ is given by (10). Substituting $u \equiv \frac{x-\mu_{x}}{\sigma_{x}}$ and

$\mathrm{w} \equiv \frac{\mathrm{y}-\mu_{\mathrm{y}}}{\sigma_{\mathrm{y}}}$ as in the proof of Theorem 1, we can write:

$F_{\mathrm{o}}=\int_{-\infty}^{\left[S-\mu_{y}\right] / \sigma_{y}} \int_{\left[S-\mu_{x}\right] / \sigma_{x}}^{\infty}\left[S-w \sigma_{y}-\mu_{y}\right] \hat{q}(u, w) d u d w$

Now substitute

$\xi \equiv \frac{\mathrm{u}-\rho \mathrm{w}}{\sqrt{1-\rho^{2}}}$ and $\mathrm{d} \xi \equiv \frac{\mathrm{du}}{\sqrt{1-\rho^{2}}}$

to write

$F_{\mathrm{o}}=\int_{-\infty}^{\left[S-\mu_{\mathrm{y}}\right] / \sigma_{y}} P(J(\rho, w))\left[S-w \sigma_{y}-\mu_{y}\right] \frac{e^{-w^{2} / 2}}{\sqrt{2 \pi}} d w$

where

$$
\begin{aligned}
& P(J(\rho, w)) \equiv \int_{J(\rho, w)}^{\infty} \frac{e^{-\xi^{2} / 2}}{\sqrt{2 \pi}} d \xi \\
& J(\rho, w) \equiv \frac{\left\{\left[S-\mu_{x}\right] / \sigma_{x}\right\}-\rho w}{\sqrt{1-\rho^{2}}}
\end{aligned}
$$

Now,

$$
\partial F_{\mathrm{o}} / \partial \mu_{x}=\int_{-\infty}^{\left[S-\mu_{y}\right] / \sigma_{y}}\left[d P / d \mu_{x}\right]\left[S-w \sigma_{y}-\mu_{y}\right] \frac{e^{-w^{2} / 2}}{\sqrt{2 \pi}} d w
$$


where

$\mathrm{dP} / \mathrm{d} \mu_{\mathrm{x}}=[\partial \mathrm{P} / \partial \mathrm{J}]\left[\partial \mathrm{J} / \partial \mu_{\mathrm{x}}\right]=\left[\frac{-1}{\sigma_{\mathrm{x}} \sqrt{1-\rho^{2}}}\right]\left[\frac{-\mathrm{e}^{-\mathrm{J}^{2} / 2}}{\sqrt{2 \pi}}\right]=\frac{\mathrm{ce}^{-\mathrm{J}^{2} / 2}}{\sqrt{2 \pi}}$

where $\mathrm{c} \equiv \frac{1}{\sigma_{\mathrm{x}} \sqrt{1-\rho^{2}}}>0$

Thus,

$$
\begin{aligned}
\partial \mathrm{F}_{\mathrm{o}} / \partial \mu_{\mathrm{x}} & =\int_{-\infty}^{\left[\mathrm{S}-\mu_{\mathrm{y}}\right] / \sigma_{\mathrm{y}}} \mathrm{ce} \mathrm{e}^{-\left[\mathrm{J}^{2}+\mathrm{W}^{2}\right] / 2}\left[\mathrm{~S}-\mathrm{w} \sigma_{\mathrm{y}}-\mu_{\mathrm{y}}\right] \mathrm{dw} \\
& =\mathrm{c} \int_{-\infty}^{\left[\mathrm{S}-\mu_{\mathrm{y}}\right] / \sigma_{\mathrm{y}}} \mathrm{e}^{-\left[\mathrm{J}^{2}+\mathrm{w}^{2}\right] / 2}\left[\mathrm{~S}-\mu_{\mathrm{y}}\right] \mathrm{dw}-\mathrm{c} \int_{-\infty}^{\left[\mathrm{S}-\mu_{\mathrm{y}}\right] / \sigma_{\mathrm{y}}} \mathrm{e}^{-\left[\mathrm{J}^{2}+\mathrm{w}^{2}\right] / 2} \mathrm{w} \sigma_{\mathrm{y}} \mathrm{dw}
\end{aligned}
$$

Define $\lambda \equiv-\mathrm{w}$ and write the above as:

$$
\begin{aligned}
\partial \mathrm{F}_{\mathrm{o}} / \partial \mu_{\mathrm{x}} & =-\mathrm{c} \int_{\infty}^{\left[\mu_{\mathrm{y}}-\mathrm{S}\right] \sigma_{\mathrm{y}}}\left[\mathrm{S}-\mu_{\mathrm{y}}\right] \mathrm{e}^{-\left[\mathrm{J}^{2}+\lambda^{2}\right] / 2} \mathrm{~d} \lambda-\mathrm{c} \int_{\infty}^{\left[\mu_{\mathrm{y}} \mathrm{S}\right] / \sigma_{\mathrm{y}}} \lambda \sigma_{\mathrm{y}} \mathrm{e}^{-\left[\mathrm{J}^{2}+\lambda^{2}\right] / 2} \mathrm{~d} \lambda \\
& =\mathrm{c} \int_{\left[\mu_{\mathrm{y}}-\mathrm{S}\right] / \sigma_{\mathrm{y}}}^{\infty}\left[\lambda \sigma_{\mathrm{y}}+\mathrm{S}-\mu_{\mathrm{y}}\right] \mathrm{e}^{-\left[\mathrm{J}^{2}+\lambda^{2}\right] / 2} \mathrm{~d} \lambda
\end{aligned}
$$

$>0$ since $\lambda \sigma_{\mathrm{y}}+\mathrm{S}-\mu_{\mathrm{y}}>0$ almost everywhere over the range of integration.

Finally,

$$
\partial \mathrm{F}_{\mathrm{o}} / \partial \mu_{\mathrm{y}}=\int_{-\infty}^{\left[\mathrm{S}-\mu_{\mathrm{y}}\right] / \sigma_{\mathrm{y}}} \mathrm{P}(\mathrm{J}(\rho, \mathrm{w}))[-1] \frac{\mathrm{e}^{-\mathrm{w}^{2} / 2}}{\sqrt{2 \pi}} \mathrm{dw}<0 .
$$

We will now show that $\partial \mathrm{F}_{0} / \partial \rho<0$. Differentiating (A-12) yields:

$$
\partial F_{\mathrm{o}} / \partial \rho=-\int_{-\infty}^{[R-\mu] / \sigma} \frac{\mathrm{e}^{-\mathrm{J}^{2} / 2}[\{\rho[\mathrm{R}-\mu] / \sigma\}-w][\mathrm{R}-\mathrm{w} \sigma-\mu] \mathrm{e}^{-w^{2} / 2}}{\sqrt{2 \pi}\left[1-\rho^{2}\right]^{3 / 2}} d w
$$

Since

$$
\int_{-\infty}^{[R-\mu] / \sigma} \frac{\mathrm{e}^{-\mathrm{J}^{2} / 2} \sigma[\{\rho[\mathrm{R}-\mu] / \sigma\}-w][\{[\mathrm{R}-\mu] / \sigma\}-\mathrm{w}] \mathrm{e}^{-w^{2} / 2}}{\sqrt{2 \pi}\left[1-\rho^{2}\right]^{3 / 2}} d w
$$


$>\int_{-\infty}^{[R-\mu] / \sigma} \frac{\mathrm{e}^{-\mathrm{J}^{2} / 2} \sigma[\{[\mathrm{R}-\mu] / \sigma\}-\mathrm{w}]^{2} \mathrm{e}^{-\mathrm{w}^{2} / 2}}{\sqrt{2 \pi}\left[1-\rho^{2}\right]^{3 / 2}} d w$

$>0$

we have $\partial \mathrm{F}_{0} / \partial \rho<0$.

Proof of Lemma 2: Using (A-14), we see that

$$
\begin{aligned}
\partial \mathrm{J}(\rho, \mathrm{w}) / \partial \sigma_{\mathrm{x}} & =\frac{-\left[\mathrm{S}-\mu_{\mathrm{x}}\right]}{\sigma_{\mathrm{x}}^{2} \sqrt{1-\rho^{2}}} \\
& >0 \text { since } \mathrm{S}<\mu_{\mathrm{x}} .
\end{aligned}
$$

Thus, we see from (A-13) that

$\partial \mathrm{P}(\mathrm{J}(\rho, \mathrm{w})) / \partial \sigma_{\mathrm{x}}<0$

which implies from (A-12) that

$\partial \mathrm{F}_{\mathrm{o}} / \partial \sigma_{\mathrm{x}}<0$

Proof of Theorem 6: We know from Theorem 2 that $\partial \mathrm{F} / \partial \sigma_{\mathrm{x}}^{2}>0$ and from Lemma 2 that $\partial \mathrm{F}_{\mathrm{o}} / \partial \sigma_{\mathrm{x}}^{2}<0$. Consider the binding constraint (14), which implies

$$
\alpha=\frac{I[1+R]}{A_{\mathrm{o}}-\eta F_{\mathrm{o}}+S}
$$

Now, let us consider the effect of increasing $\sigma_{\mathrm{x}}^{2}$, holding $\alpha$ fixed. Since $\partial F_{\mathrm{o}} / \partial \sigma_{x}<0$, we have $\partial \alpha / \partial \sigma_{\mathrm{x}}<0$. Thus, to keep $\alpha$ unchanged when $\mu_{\mathrm{x}}$ increases, $\eta$ must increase. This means that an increase in $\sigma_{x}$ allows the participation constraint (14) to be satisfied with a higher $\eta$, leaving $\alpha$ unchanged. Moreover, the objective function (13) is increasing in $\eta$. Thus, holding $\alpha$ fixed, the entrepreneur can increase his expected payoff by increasing $\eta$ and not violate the participation constraint (14). At the higher $\sigma_{\mathrm{x}}$ then, the entrepreneur will choose a higher $\eta$. 
Proof of Theorem 7: As we showed in the discussion preceding the theorem, when

$\beta_{i}>\max \left\{\beta_{i}^{+}, \mathrm{F}_{\mathrm{o}}\left[\mathrm{F}+\mathrm{F}_{\mathrm{o}}\right]^{-1}\right\}$, the value-maximizing solution is to set $\eta_{\mathrm{i}}=\eta_{\mathrm{i}}^{*}=1$. That discussion also showed that when $\beta_{i}$ is low enough to satisfy $\beta_{i}<\min \left\{\beta_{\mathrm{i}}^{-}, \mathrm{F}_{\mathrm{o}}\left[\mathrm{F}+\mathrm{F}_{\mathrm{o}}\right]^{-1}\right\}$, the valuemaximizing solution is to set $\eta_{i}=\hat{\eta}_{i}>0$ (where $\hat{\eta}_{i}$ is the value of $\eta_{i}$ for which (24) holds as an equality) only if $\Omega\left(\hat{\eta}_{\mathrm{i}}\right) \geq 0$, and to set $\eta_{\mathrm{i}}=0$ if $\Omega\left(\hat{\eta}_{\mathrm{i}}\right)<0$. 


\section{REFERENCES}

Admati, Anat and Paul Pfleiderer, (1994), "Robust Financial Contracting and the Role of Venture Capitalists", Journal of Finance 49, pp. 371-402.

Aghion, Philippe and Patrick Bolton, (1997), "Incomplete Social Contracts", mimeo, Harvard University.

Aghion, Philippe and Jean Tirole, (1997), "Formal and Real Authority in Organizations", Journal of Political Economy 105-1, pp. 1-29.

Aghion, Philippe, Alberto Alesina and Francesco Trebbi, (2002), "Endogenous Political Institutions", Working Paper, Harvard University.

Akerlof, George A., (1970), "The Market for Lemons: Quality Uncertainty and the Market Mechanism”, Quarterly Journal of Economics 84, pp. 488-500.

Alicke, Mark D. and Kevin Doherty, (1992), "Social Disagreement and Conformity", Journal of Social Behavior and Personality 7-1, pp. 125-137.

Allen, Franklin and Douglas Gale, (1994), Financial Innovation and Risk Sharing, Cambridge: MIT Press, 1994.

Allen, Franklin and Douglas Gale, (1999), "Diversity of Opinion and Financing of New Technologies", Journal of Financial Intermediation 8, pp. 68-89.

Aumann, Robert J., (1976), “Agreeing to Disagree”, Annals of Statistics 4-6, pp. 1236-39.

Bamber, Linda, S., Orie E. Barron and Thomas L. Stober, (1997), "Trading Volume and Different Aspects of Disagreement Coincident with Earnings Announcement", The Accounting Review 72-4, pp. 575-597.

Barro, Robert J., (1986), "Recent Developments of the Theory of Rules versus Discretion", Economic Journal 96, pp. 23-57.

Berlin, Mitchell and Loretta J. Mester, (1992), "Debt Covenants and Renegotiation", Journal of Financial Intermediation 2, pp. 95-133.

Blackwell, David and Lester Dubins, (1962), "Merging of Opinions with Increasing Information", Annals of Mathematical Statistics 37, pp. 686-689.

Bonanno, Giacamo and Klaus Nehring, (1997), “Agreeing to Disagree: A Survey”, SSRN Working Paper No. 97-18, University of California at Davis, June.

Boot, Arnoud, W.A., Stuart Greenbaum and Anjan V. Thakor, (1993), "Reputation and Discretion in Financial Contracting", The American Economic Review 83-5, pp. 11651183.

Boot, Arnoud, W.A. and Anjan V. Thakor, (1993), "Security Design", Journal of Finance 48-4, pp. 1349-1378. 
Chan, Yuk-Shee, Daniel Siegel and Anjan V. Thakor, (1990), "Learning, Corporate Control and Performance Requirements in Venture Capital Contracts", International Economic Review 31, pp. 365-381.

Child, Peter, N., (2002), “Taking Tesco Global”, The McKinsey Quarterly, No. 3.

Chowdhry, Bhagwan, Mark Grinblatt and David Levine, (2002), "Information Aggregation, Security Design, and Currency Swaps”, Journal of Political Economy 110-3, pp. 609633.

Clarke, Ian and William Mackaness, (2001), "Management 'Intuition': An Interpretative Account of Structure and Content of Decision Schemas Using Cognitive Maps", Journal of Management Studies 38-2, pp. 147-172.

Crawford, Vincent, P., (1982), "A Theory of Disagreement in Bargaining”, Econometrica 50-3, pp. 607-638.

Farber, Henry, S. and Max H. Bazerman, (1989), "Divergent Expectations as a Cause of Disagreement in Bargaining: Evidence from a Comparison of Arbitration Schemes", The Quarterly Journal of Economics 104-1, pp. 99-120.

Flannery, Mark and Kasturi Rangan, (2002), "Market Forces at Work in the Banking Industry: Evidence from the Capital Buildup of the 1990s", Working Paper, University of Florida, February.

Fuchs, Victor, R., Alan B. Krueger and James M. Poterba, (1997), "Why Do Economists Disagree About Policy? The Roles of Beliefs About Parameters and Values", NBER Working Paper No. w6151, August.

Fulghieri, Paolo and Dmitry Lukin, (2001), "Information Production, Dilution Costs, and Optimal Security Design”, Journal of Financial Economics 61-1, pp. 3-42.

Garmaise, Mark, J., (2001), "Rational Beliefs and Security Design”, Review of Financial Studies, 14-4, pp. 1183-1213.

Goldfeld, Stephen M., (1982), "Rules, Discretion and Reality", American Economic Review 72, pp. 361-366.

Gompers, Paul and Josh Lerner, (1998), "Venture Capital Distributions: Short Run and Long Run Reactions”, Journal of Finance 53, pp. 2161-2183.

Gompers, Paul and Josh Lerner, (1999), The Venture Capital Cycle, Cambridge: MIT Press.

Higashide, Hiromori and Sue Birley, (2002), "The Consequences of Conflict between the Venture Capitalist and the Entrepreneurial Team in the United Kingdom from the Perspective of the Venture Capitalist", Journal of Business Venturing 17-1, pp. 59-81.

Hirshleifer, David, Seongyeon Lim and Siew Hong Teoh, (2002), "Disclosure to a Credulous Audience: The Role of Limited Attention", Working Paper, Ohio State University, February. 
Holmstrom, Bengt, (1979), "Moral Hazard and Observability", Bell Journal of Economics 10, pp. 74-91.

Jensen, Michael C. and William Meckling, (1976), "Theory of the Firm: Managerial Behavior, Agency Costs and Ownership Structure", Journal of Financial Economics 3, pp. 305360 .

Jensen, Michael C., (1986), "Agency Costs of Free Cash Flow, Corporate Finance, and Takeovers”, American Economic Review 76, pp. 323-329.

Kahneman, Daniel and Dan Lovallo, (1993), "Timid Choices and Bold Forecasts: A Cognitive Perspective on Risk-Taking", Management Science 39-1, pp. 17-31.

Kalai, Ehud and Ehud Lehrer, (1993), "Rational Learning Leads to Nash Equilibrium", Econometrica 61, pp. 1019-1045.

Kalai, Ehud and Ehud Lehrer, (1994), "Weak and Strong Merging of Opinions", Journal of Mathematical Economics 23, pp.73-86.

Kalai, Adam and Ehud Kalai, (2001), "Strategic Polarization", Journal of Mathematical Psychology 45-4, pp. 656-663.

Kandel, Eugene and Neil D. Pearson, (1995), "Differential Interpretation of Public Signals and Trade in Speculative Markets", Journal of Political Economy 103, pp. 831-872.

Kurz Mordecai, (1994a), "On the Structure and Diversity of Rational Beliefs", Economic Theory 4, pp. 877-900.

Kurz Mordecai, (1994b), “On Rational Belief Equilibria”, Economic Theory 4, pp. 859-876.

Kydland, Finn E. and Edward C. Prescott, (1977), "Rules Rather than Discretion: The Inconsistency of Optimal Plans”, Journal of Political Economy 85, pp. 473-492.

Lowe, Janet, Jack Welch Speaks: Wisdom from the World's Greatest Business Leader, New York: John Wiley and Sons, 1998.

Maskin, Eric and Jean Tirole, (2001), "The Politician and the Judge: Accountability in Government", mimeo, MIT.

Miller, Ronald, I. and Chris W. Sanchirico, (1997), "Almost Everybody Disagrees Almost All the Time: The Genericity of Weakly Merging Nowhere", Columbia Economics Department Discussion Paper Series No. 9697-25.

Modigliani, Franco, (1964), "Some Empirical Tests of Monetary Management and of Rules versus Discretion”, Journal of Political Economy 72, pp. 211-245.

Morris, Stephen, E., (1995), "The Common Prior Assumption in Economic Theory", Economics and Philosophy 11, pp. 227-253. 
Mullainathan, Sendhil and Andrei Shleifer, (2002), "Media Bias", NBER Working Paper 9295, October

Myers, Stewart and Nicholas Majluf, (1984), "Corporate Financing and Investment Decisions When Firms Have Information That Investors Do Not Have", Journal of Financial Economics 13, pp. 187-221.

Prendergast, Canice, (1993), “A Theory of 'Yes Men””, American Economic Review 83, pp. 757770.

Prendergast, Canice, (1999), "The Provision of Incentives in Firms", Journal of Economic Literature 37, pp. 7-63.

Prendergast, Canice, (2002), "The Tenuous Trade-off Between Risk and Incentives”, Journal of Political Economy 110-5, pp. 1071-1102.

Rajan, Raghuram and Andrew Winton, (1995), "Covenants and Collateral as Incentives to Monitor", Journal of Finance 50, pp. 1113-1146.

Schweizer, Berthold and E.F. Wolff, (1981), "On Non-parametric Measure of Dependence for Random Variables", The Annals of Statistics 9-4, pp. 879-885.

Stumpf, Steve A. and Roger L.M. Dunbar, (1991), "The Effects of Personality Type on Choices Made in Strategic Decision Situations”, Decision Sciences 22-5, pp. 1047-1072.

Tadelis, Steven, (2002), "Complexity, Flexibility, and the Make-or-Buy Decision," American Economic Review (AEA Papers and Prodeedings) 92-2, pp. 433-437.

White, R., (1971), “Selective Inattention”, Psychology Today 82, pp. 47-82. 